\title{
Digital Transformation through Collaborative Platformization: A Study of Incumbent-Entrepreneur Relations
}

\author{
Katja Maria Hydle \\ University of Oslo \\ katjahy@uio.no
}

\author{
Ole Hanseth \\ University of Oslo \\ oleha@ifi.uio.no
}

\author{
Margunn Aanestad \\ University of Agder \\ margunn.aanestad@uia.no
}

\author{
Tor Helge Aas \\ University of Agder \\ tor.h.aas@uia.no
}

\begin{abstract}
The paper examines the unfolding of digital transformation in and the platformization of an industrial firm. To enable transformation despite a complex and heterogeneous IT landscape, a platformization strategy was followed and an entrepreneurial firm was established to be the strategic partner in the transformation journey. We examine the collaboration between the two firms based on empirical material covering the period 2016-2020. The paper contributes to the literature on digital transformation, as it illuminates the dynamic role of strategic partnerships in such processes. We also contribute to the literature on digital platforms and collaborative nature of governing the process of platform development by identifying three modes of collaborating and adapting.
\end{abstract}

\section{Introduction}

Digital transformation has become a core issue for most organizations as a result of the growing variety of digital technologies and solutions which offer opportunities for new business models, strategies and ways of organizing. In a recent survey among European IT executives, digital transformation was coined the third most important issue for management of IT [1]. Accordingly, digital transformation has also become a focused topic of recent IS and management literature [2-5]. We understand digital transformation within an organization as encompassing both the strategy, structure and technology domains [6, 7].

Digital transformation is often challenging due to the increased complexity of the organizational IT landscape $[8,9]$. Huge numbers of IT solutions support virtually all organizational activities and work processes, while the individual solutions are integrated with a growing number of others - within as well as outside of organizational boundaries. The various solutions are usually developed, maintained and operated by different vendors, consultancies and internal IT units working in a complex mix of collaborative arrangements. This growing complexity is in many organizations experienced to be costly and virtually impossible to adapt to being aligned with the aims and visions of digital transformation programs.

The complexity of transforming large and distributed organizations and their portfolio of IT solutions has been researched within the information infrastructures stream of research [10-14]. More recently, however, due to the popularity of digital platforms and the enormous success of platform companies [15], organizations have started to explore how changing their complex organizational IT landscape solutions towards a platform architecture may make the organizations more innovative and profitable $[8,9,16,17]$. In this context, a platformoriented infrastructure, as described e.g. by Bygstad and Hanseth [17], implies the establishment of a platform core and the provisioning of interface resources (like SDKs and APIs). In this context, the platform is a set of digital resources that enable a looser coupling between the various components in the IT landscape. There are relatively few studies of such platformization processes of converting a traditional organizational IT landscape into a platform. In particular, there are even less studies that study which organizational capacities and competencies are required and how these are acquired or established. We argue that this is a crucial aspect to understand, and we will contribute to this stream of research by an empirical study of an ambitious digital transformation program of a large industrial company which sought to build a platform-based IT infrastructure. Our focus will be on how the industrial firm developed strategic collaboration with an entrepreneurial firm for the platform development. Our research question is: How does platformization unfold as collaborative processes between industrial firms and strategic partners? Through this study we aim to contribute to the literature on platformization processes with an empirical study of the collaborative relations involved 
and their strategic significance. In the following sections, we review relevant literature on digital transformation, platform-oriented infrastructures and governance, before we account for the empirical study in Section 3. The findings are presented chronologically in Section 4, while we in Section 5 discuss three modes of collaborating and continual adapting between the industrial firm and the strategic partner contributing to platformization literature, platform governance theorizing and to the understanding of digital transformation.

\section{Related research}

\subsection{Digital transformation}

The concept of digital transformation reflects a substantial change in the role that digital technologies play for individuals, organizations and the society as a whole. In a recent literature review by Vial [5:118], digital transformation has been defined as "a process that aims to improve an entity by triggering significant changes to its properties through combinations of information, computing, communication, and connectivity technologies". Hinings et al. [3: 52] provide a slightly different definition, relating digital transformation explicitly to digital innovation, practices, at various levels of analysis, by defining it as: "the combined effects of several digital innovations bringing about novel actors (and actor constellations), structures, practices, values, and beliefs that change, threaten, replace or complement existing rules of the game within organizations, ecosystems, industries or fields". In this paper, we adopt Hinings et al.'s definition of digital transformation, to look at how the restructuring of an organization's portfolio of IT solutions, into a platform ecosystem play out. This definition clearly underscores the socio-technical character of digital transformation, indicating that skills, organizational capabilities and involved practices and social structures, are important for the results of digital transformation processes.

These social relations of digital transformation processes are significant, but understudied. Most organizations' IT solutions imply relation to a large number of vendors, and the inter-relations between the various solutions create complex socio-technological structures embedding considerable inertia which may inhibit organizational change. Thus, we argue that successful digital transformation will require managing various socio-technical tensions. In the following two sections we will explicate first tensions related to the complex IT portfolios, and secondly, the complex actor constellations.

\subsection{Platform-oriented infrastructures}

The complexity of IT landscapes has been addressed by the research stream of information infrastructures; a concept used to analyze large portfolios of IT solutions within organizations, interorganizational and sector-wide solutions as well as global structures like the Internet and mobile phone infrastructures. In this literature, top-down and centrally control-oriented approaches are found to often be counter-productive, while more agile and flexible approaches are more successful $[10,12]$. More recently digital platforms, platform-oriented infrastructures and ecosystems have become widespread. These architectural patterns allow a more decoupled and flexible approach. Platform approaches have therefore spread beyond social media and consumer-oriented platform also to corporate IT landscapes. For instance, commercial software products have become "platformized" and opened for third party developers in order to expand the market and user base through growing ecosystems of apps and app developers around them [18]. Also, user organizations have started to employ platform notions when restructuring their application portfolios $[8,9$, 17, 19].

We are here interested in the process of such "platformization" of an organization's internal IT landscape. Platformization, as understood by Benlian, et al [19, p. 374] "builds on decoupling and characterizes the process in which an entity (a provider organization) creates access and interaction opportunities centered around a core bundle of services (the platform) within an ecosystem of consumers, complementors, and other stakeholders". Törmer and Henningsson [8] have studied how an industrial company (the Lego group) transformed their existing IT solutions into platforms in order to facilitate more innovations and internationalization [21]. They define platformization as "the sociotechnical process of transforming a large-scale IS towards a platform architecture. This architecture is characterized by a core of stable functionality, a periphery of increasingly variable components, and component interactions via standardized, de-coupled interfaces" [20; p. 5781]. Platformization is also a key theme in the study by Gregory, et al. [19], who describe how a large global bank introduced a digital service platform which spurred a shift to platformbased IT governance.

However, the existing studies do not provide much detail on how the existing solutions actually were transformed. Bygstad and Hanseth [17] offer a more granular description in their analysis of a long-term 
program aiming at transforming a complex portfolio of about 5700 IT solutions in a hospital organization into a more manageable structure. The resulting "platformoriented infrastructure" could successfully serve as the basis for the transformation of the IT portfolio. However, also in this account the main focus is on the architectural strategy and evolution, rather than on the social relations between the organization and its vendors.

\subsection{Governing platformization processes}

These relations have gotten some more attention in the platform literature. Establishing platforms also comprise governing the multiple actors involved in different roles. Constantinides, et al. [15] argues that the process of platformization concerns the theme of governance: "Infrastructures are undergoing a process of platformization as architectural and governance control points are opened through digitization" (p. 386). The actor dynamics around these "control points" are the topic of much IS literature on platforms that focus on platform governance [e.g. 18, 22, 23-25]. The main focus has been on the definition of decisionmaking rights of platform owners and app developers, control mechanisms, incentive structures and the boundary resources within which these are embedded, mainly seen from the platform owners' perspective with less attention to the third party or complementor [26]. Moreover, while disagreement and tussles have been described [e.g. 24, 25], there is less focus on the collaborative nature of the relation between the platform owner, complementors and platform users.

We argue that IS research would benefit from a better understanding of how complex and dynamic collaborative relationships emerge and evolve around the development of digital platforms.

\section{Methods}

\subsection{Case background}

Due to the nature of the research question we conducted an in depth empirical, qualitative study to explore the collaborative relations around platformization in an industrial firm called Indus (anonymized). The firm is a significant actor in the oil and gas production industry that has focused intensively on platformization together with strategic partners in recent years. An in-depth study of this case is therefore particularly relevant to gain insight about how industrial platformization unfold as collaborative processes.
Indus has grown through merger and acquisitions over several years. This resulted in a complex and heterogeneous IT portfolio, and a realization that there was a potential to utilize existing digital technologies more systematically through a data-centric approach where data from different data sources, such as digital sensors on the oil platforms, are integrated.

This turned out to be practically challenging given the fragmented IT landscape, and in 2016 Indus therefore searched for external strategic partner candidates that could support them in their platformization process. The search was not fruitful and resulted in the decision to instead support the establishment of a new company. A well-known digital entrepreneur was encouraged to establish a firm which we here call Digitize (anonymized). Digitize was established in 2016 with only a few employees. After 3 years of operation, Digitize counted 300 employees from 20 different countries, and has been able to recruit highly sought after data scientists and digitalization consultants also from international markets. Indus has maintained its in-house IT department, which has the responsibility for operational IT, while the strategic platformization development has been pursued in collaboration with Digitize.

\subsection{Data collection}

In our ongoing study of the digital transformation in Indus, we have so far conducted 9 interviews in Digitize and 2 in Indus (with senior managers, middle managers and employees working with platformization). The interviews sought to capture oral histories of the background, the unfolding of platformization and the process of collaboration retrospectively and were conducted in 2019 and 2020 covering the period from 2016 to 2020 . The interviews were semi-structured, lasted between 1 and 1.5 hours and were verbatim transcribed. In addition, we have so far had three meetings with middle managers in Digitize discussing the research and the preliminary findings to validate the veracity of the empirical material and enhance the trustworthiness of the analysis [27].

\subsection{Data analysis}

A comprehensive case story was written and used to discuss the findings among the researchers involved. The findings were coded open-ended by using NVivo 12. We developed coding frames that reflected emerging themes from the empirical material and coded the material accordingly. The material was examined with attention to the collaboration between 
Digitize and Indus and the unfolding of the digital transformation. Using an in-depth analysis of the empirical material and existing theory [28], we paid attention to surprises leading us to further theorizing [29]. We were first surprised by how the processes of platformization exposed that there were continual adaptations of both the digital innovations and of the modes of collaboration between Indus and Digitize, resulting in the unfolding of platformization. Such constant tailormade adaptations of digital innovation are similar to the denoted dynamic problem-solution design pairing and matching in existing theory [30]. A related surprise, was how connected and interdependent the relationship evolved between Indus and Digitize, centering around data-related and value adding capabilities. The platformization processes were found to be a collaborative endeavor. These findings which are described below, form the basis of our contributions.

\section{Findings}

\subsection{Initiating platformization in Indus}

The company Digitize was co-founded by Indus. The idea was that Digitize would develop and own the digital platform needed for Indus' digitalization, which required data fusion capabilities from a heterogenous, multi-actor underlying the IT landscape.

A senior director explained: "Digitize started as a project within Indus, and the [future] CEO was contacted by Indus and then they created a company with Indus [on the owner side] ...The premise from Indus was that they should own their data, although it should be easily accessible to everyone. They [Indus] do not want to own the software.... Indus does not look at software as a competitive advantage; their competitive advantage is oil related understanding. If Digitize had been internal to Indus, it would have been very expensive..."

Indus was the first customer of Digitize. Indus wished to outsource the IT development and capabilities required to develop and maintain the data platform, for several reasons. While they would maintain ownership to their own data, they would also seek to generate desired efficiencies by opening the platform. The physical infrastructure on e.g. an oil platform is comprised of digi-physical devices from a number of vendors, who have continuing relations to Indus e.g. through service agreements. Making available data, e.g. from equipment sensors, would also carry potential for these actors to benefit. Therefore, the intention and expectation were that Digitize's evolving data platform would become a resource also for third-party vendors. A manager explained: “...what we have tried to do is to bring in a lot of third parties in this environment who will develop these applications, who will then be involved in investing and bearing their cost in developing this".

Digitize has successfully grown and has been able to brand itself as an attractive digital company. Thus, the company has been able to hire highly qualified talents, both data scientists and experienced consultants from international consultancy firms and competitors; staff that Indus itself as an oil industry incumbent would not be able to attract. The staff is diverse, around 150 employees (50\%) work in Engineering, while the remaining work in the Customer Success Department, as advisors, consultants and project managers. At the time of our study, a significant proportion of the staff (one third) worked hands-on with platform and software development. This work was done in tight collaboration with a team from Indus. We now turn to describing the evolution of this collaboration.

\subsection{Developing a joint work model}

Digitizes initial goal was to create software enabling Indus to implement its digital strategy; therein lies a very close partnership between Digitize and Indus. Both companies knew what the challenges were, related to under-utilized digital opportunities and the need for digital transformation. However, where to start and how to go about, was not equally clear. A manager described the situation as follows: "It started with the goal of creating this Software product to enable Indus' digital strategy. So therein lies a very close partnership that is not a clear delivery. One knew what the challenges were, but one did not know what the solution was." In addition, Indus had limited competence of the digital possibilities, while Digitize had limited competence of the oil and gas industry.

Digitize started to build the platform technology in parallel with extracting different 'use cases' from Indus. Across all business areas and disciplines, Indus identified different use cases that helped to identify ideas and potential usage of a data platform. However, both firms realized that this approach lacked direction and focused too much on the technology rather than on the digital transformation and value adding changes; it did not lead to any changes in the actual workflow which would add value. A senior manager in Indus explained: "The main challenge is not the technology. The main challenge is to make sure that we are actually able to extract value by using new technology. Because when you have managed to create some Software on top of the Digitize platform, then you have done $10 \%$ of the job. What is really demanding is 
changing work processes so that you are actually able to extract value (...)."

To counter this, Indus created a large unified and centralized digitalization program in the summer of 2018, which we here call "Transform". Between 150 and 170 Indus employees participated in this program by the end of 2019 (i.e. a significant proportion of Indus total 1700-1800 employees and 600 consultants). A Program Management Office (PMO) was established to have a coordinating, orchestrating and facilitating role for the Transform program, as well as being responsible for prioritizing activities and allocating resources to these activities. Initially, the PMO was also responsible for the budget and the financial control of the program, but this responsibility was transferred to the business units of Indus in 2020. A manager of Indus stated: "We in the Transform program work a lot to change the organization strategically ... we are the engine of the digital transformation". This also changed the mode of collaborating.

\subsection{The co-development processes}

The two companies then decided to work together using what they presented as an agile software development process with two week long sprints and 16 weeks super-sprints. Each super-sprint aimed to solve a set of problems, while the aim of each sprint was to deliver something concrete. During the sprints, meeting activities were limited to short daily sprint planning meetings.

A manager in Digitize explains the development process in the following manner: "It is a "stage cut process", which is managed, with an evaluation after the 16 weeks. "Did we reach our goals? Who should join?" Then you plan again and bring in new problems. Such an agile team runs two-week sprints [...] with a "gate" in the middle of which they call in the sponsor group of the corporate management and provide an update on where they are and receive some questions and challenges in the direction. Then, for the rest of the period, they get a full-day session called "in sprint" where they have to explain what they have accomplished and defend it. The management mechanism is that they have to ask for money before you start, explain what kind of problem you are going to solve, what is your budget, resources, third parties, and so on." The top management and the CEOs of both Indus and Digitize were involved in the "in sprint" of the sprints when deciding on the future direction.

The first super-sprint focused on the data platform and involved contributions from data scientists. While the attention was towards value-generating development, this became an even stronger focus in the second super-sprint. In this super-sprint an "Operation Support" application were developed. This was in itself a value-adding and problem-solving application. However, it was also intended to ignite the external success of the platform itself, as the idea was that the development of a few demo-applications would inspire third parties to develop other more novel applications. Digitize had not aimed to become an application developer. However, the involvement of third parties turned out to be difficult, and consequently Digitizes application development activities turned out to be more comprehensive than anticipated. One explained the situation with third parties as follows: "The supplier market is much more immature than we had thought. We had thought that when we started getting data into Digitize that everyone would knock on the door to sell us their product, which we could plug in at the top. It does not quite happen like that."

In the third super sprint, there were two major focuses: (1) to go beyond the previous focus on oil platform-based needs and possibilities and venture into identifying opportunities also in the sub-sea area; (2) to develop a "Software Asset Service product". In 2020, the focus has been on changing work processes by becoming more data-driven in everything they do, e.g. by shifting from scheduled preventive maintenance of physical components to condition-based maintenance.

\subsection{Organizing for co-development}

Digitize and Indus had a close partnership at all levels, from the CEO level (with frequent formal and informal interactions) and down to the actual working groups. While the digital platform was at the core of Digitize's offer, many of Digitize's employees were ex-consultants who managed large digitization programs, and they considered themselves to also be a service provider who assisted Indus in changing internal processes. One explained: "We act both as a bit of advisors and a bit of a driving force, in the sense that we as Digitize are quite heavily involved in this project."

Many teams had a mix between Digitize and Indus employees. Together with Indus, the teams (called crews) were set up to collaborate closely with the users and the offshore platforms. For example, there was a "crew leader", who was Digitize's leader for one of the industrial solutions called the "Digital Worker" program. For the development of these Digital Worker solutions for Indus, the responsible was called "Captain", while a Digitize employee was denoted "Co-Captain" of the program. The leaders had a lot of discussions within the crews. An employee from Indus explained: "The crew lead insists that they should not talk about "us" and "you" because it is "we", but at the 
same time Digitize are aware of their own agenda. They each have their hats on, but with common goals, being responsive to each other's skepticism and reservations and have good discussions. Then there's room to ask, "But why? I do not understand this. I disagree"."

The co-captains in the different crews being Digitize employees, worked as advisors and drivers for Indus, but also as challengers. They questioned established ways of doing things and challenged Indus on how things can be done differently. A Digitize product manager explained: "How should these new solutions be implemented in the organization? It's not just about pushing small products, expecting them to be used. So, we work there as a little door opener, a little bit of adviser, a little ... well, create a little storm in the glass then. But that's only to start the processes. After all, it's so easy to just resort to the old way of working".

The co-development of the platform, was also accentuated by the physical locations. Digitize's main offices are located on the floor below Indus. The crews themselves were co-located with the developers, e.g. the entire Digitize "Operation Support Team", who developed Digitize's main products. Moreover, two mechanics from Indus who earlier had worked offshore, were placed in the offices of Digitize and were involved in the development on a daily basis. One of the team members from Digitize exemplified how the operational role of the two mechanics plays out in the everyday work: "Is this something we should focus on for the next two days? Is there something that gives you something? Does it solve something?" "No". "Okay, then we'll find something else". In addition, Digitize has frequent contact with end users (on oil platforms) either by mail, telephone, skype or through physical visits, which they do several times a year, lasting from 3-5 days.

For Digitize, Indus was the first and the most mature customer they worked with. Later they have also brought their data platform to other sectors beyond oil and gas, such as the energy sector and manufacturing.

\subsection{Platform for solving industrial challenges}

Digitize has built a platform, based on the tight collaboration with Indus, that collects and assembles various types of industrial data from about 40 (heterogeneous and siloed) source systems (see figure 1). "The first thing we looked at in Digitize was whether the technical system was capable of handling the industrial system. There were many systems that handled some systems, some 3D models well, but not the whole system in a good way ... There were a large number of different systems; 4 different system portfolios with 700 different systems that give an indication of the complexity. What are the most important systems for Indus? ... We started by looking at the production side, which had to do with the fact that this was valuable data, and it was ok systems to start with that were in place, and therefore gave fast results, and we could test out the ideas pretty fast ... We have around 40 integrations". The data model is centered on assets (physical objects). After collecting and preparing data from the underlying source systems, the platform contextualizes and refines them, i.e. mapping the assets and linking them together based on how they are actually connected (e.g. in relation to a physical flow of fluids).

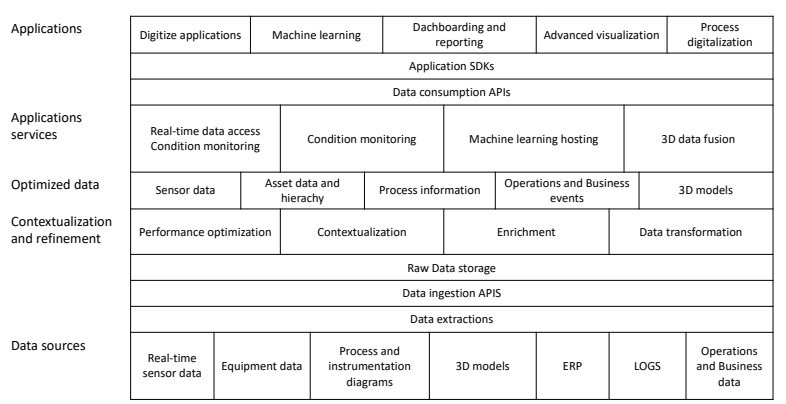

Figure 1. Digitize platform architecture

A user can do a number of searches, queries and filtrations. The application services can make predictions from machine learning modules, simulators or large 3D data that can be viewed in a user-friendly way on a phone. The platform content is available through an API, without exposing the technology used within the platform. Digitize also have connectors and software development kits from many different programming languages and analytical tools for others to build web applications on top of the platform. Some of these applications have been developed by Digitize to be able to extract value for their customers.

On top of the platform are the industry solutions. The industrial challenges Digitize wants to solve are: 1) Predictive Maintenance (where scheduled proactive or reactive maintenance is replaced by data- and AIsupported indications of need for maintenance); 2) Product Optimization (using relevant data from the platform during production processes, to increase capacity); 3) Digital Worker (equipping employees and field workers with advanced technology to perform their job); 4) Sustainability (enabling data-driven operations, using real-time analytics and sensors, which in turn may reduce the environmental impact by increasing productivity while reducing waste), and; 5) Business Transformation (improving external collaboration with manufacturers and suppliers in the 
ecosystem through access to operational data). In the following, we expose one of these industrial solutions, Digital Worker, to illustrate how the platform works for Indus and how this industrial solution was codeveloped.

\subsection{Enabling the Digital Worker}

To understand the needs of the offshore workers, to identify which work processes could be digitally transformed and to enable the digital innovation named the "Digital Worker", Digitize used a design-driven process with extensive on-site presence, observation of work and engagement with the users. Employees from Digitize travelled out to Indus offshore oil platforms, talked to the end users and identified the challenges and issues. The purpose of the dialogues with the end users was both to engage them and to learn about a context with which they were unfamiliar. "It's not just about engaging the end user. When the offshore worker stands out there in the storm, it is freezing and raining, wearing heavy gloves, glasses and a helmet and having to use a regular cell phone. Extreme demands are placed on the product and the solutions in business-tobusiness". Indus has selected two mechanics who usually work offshore, to be physically present in Digitizes offices as a resource in the design process. User discussions and demos are run either from the offices over Skype, or physically at the platforms offshore. Digitize try to visit all the offshore locations at Indus once every six months and talk to all three shifts on the platform.

The "Digital Worker" gives field workers (e.g. staff on oil platforms) a secure handheld device, a phone. A Digitize middle manager explained: "...they have access to all the documents that they previously had to run back and forth to print. They have access to trends on equipment that emits some value, whether it's temperature or pressure or something. [...] They get a map on the phone of where the equipment they are going to investigate is. [...] They always have a camera with them. They can document things much better by taking pictures and videos. [...] They have brought Skype into the field. [...] You can submit observation cards over the phone. You can bring up the "Business Management" system of Indus and see how the process is. You can also get chemical data sheets. [...] If you are going to change oil on an equipment, you can see what type of oil is required on that equipment and how much is to be refilled."

The technology behind the Digital Worker support is comprehensive, as it requires an asset hierarchy, process diagrams and $3 \mathrm{D}$ models, to be able to contextualize events logs and time series of data. As explained by an employee: "... what we really do and what is really the deal with Digitize is the contextualization that builds all this together." Digitize and Indus believe that the idea behind the Digital Worker for offshore may be relevant to other industries, and they seek to create solutions that are scalable and relevant for several other capital-intensive industries.

\section{Discussion}

The objective of this paper is to contribute to the understanding of how platformization unfold as collaborative processes between industrial firms and strategic partners. Our findings suggested that there were continual adaptations of both the digital innovations and of the modes of collaborating. These adaptations were: 1) performed through the super sprints between the platform developer, the platform owner and the platform users, and the design-driven processes for the industry solutions between the platform developer and the platform users; 2) enabled by matching functions in the parallel structure in the crews developing the platform from both Indus and Digitize, and enabled by close partnerships from the CEO level to the offshore mechanics from Indus and platform developers from Digitize working together during the platform development, and; 3) facilitated by both companies being co-located and working together. Digitize and Indus had different roles, competency profiles and identities. Still, the collaboration was extensive at all levels from the CEO to the employees offshore. The participants in the digital transformation process were co-located in the same building and worked together, thus the journey of change was talked about as "us" and walked together as one entity.

These three modes of collaborating and continual adapting between the industrial firm Indus and the strategic partner Digitize, namely performed through collaborative processes, enabled by close partnerships and facilitated by working together, constitute the papers main findings. The paper contributes to platformization theorizing by providing empirical details on how existing solutions were transformed. Existing studies have exposed that companies transform their IT solutions into platforms [8, 19] and the architectural strategy and evolution of platformization [17], while our contribution adds knowledge on the social relations between the organization and its vendors. Our contribution thus highlights how platformization is enabled and reached through continual adaptation and collaboration processes. Törmer and Henningsson [8] define platformization as "the socio-technical process of transforming a large-scale IS towards a platform 
architecture. This architecture is characterized by a core of stable functionality, a periphery of increasingly variable components, and component interactions via standardized, de-coupled interfaces" [20; p. 5781]. We add to this definition stating that the socio-technical processes of transformation involving complex actor constellations are performed through collaborative processes, enabled by close partnerships and facilitated by working together.

The case also contributes to platformization literature that addresses the issue of governance. While the majority of studies center on the often-adversarial relation between platform owner and other stakeholders, there is less attention to the collaborative aspects of such relations. We believe this oversight may be a consequence of many platform studies being done in a B2C context. In B2B settings, more distributed and collaborative arrangements may be required [31]. In these settings, digital transformation often involves servitization and inherent business models innovation [32], centered on data exchange and data-related capabilities [33, 34]. We found that digital transformation in a B2B context implies a connected and interdependent relationship between the firms involved. Our contribution expose that the interdependent and dynamic collaborative relationships are performed through collaborative processes, enabled by close partnerships and facilitated by working together. This goes beyond providing complementary offerings to a platform core, and reveals other, more complex and more central entrepreneurial opportunities. Seen from the incumbent side, our study shows that platformization may be a feasible strategy to achieve digital transformation in a situation of existing IT complexity. This strategy, however, requires the development of new organizational patterns involving close collaborative partnerships and introduce novel dependencies on external partners. We found that platformization was an emergent and dynamic process enabled through collaborative relationships between the actors.

The case illustrates that platformization is a nontrivial undertaking and a long journey. It also illustrates that structuring an organization's IT portfolio with a platform at the center may be a powerful strategy for achieving such a transformation. As Indus' IT landscape was made up by many systems from different vendors, it is difficult to imagine that a joint transformation process could have been conducted with all of them simultaneously. Establishing the platform layer allows Indus to decouple the transformation process from this complexity, and only relate to one actor instead of e.g. 40 sub-vendors. Then only adapters for transferring the relevant data between the platform and the existing solutions were needed, and accordingly, Indus was primarily dependent only of the work of one software vendor. However, in line with the traditional idea of platform ecosystems, both Indus and Digitize wanted to attract third parties that would be innovative and develop apps making important contributions to the digital transformation program. So far, this idea did not materialize as well as planned. However, as Digitize extends the "generification" of its platform by moving into new sectors, this picture may change.

The paper also contributes to digital innovation and digital transformation theorizing. Our case illustrated that the organizational transformation of an industrial incumbent involved constant adaptation of digital innovation, supported by an entrepreneurial strategic partner being integral to the unfolding. Existing theory within digital innovation claims that collaboration and relationships between entrepreneurial firms and incumbents in open innovation and the platform context, is complex and involve relational capabilities [35]. Our findings support this claim, while further extending these insights by exposing that there are three modes of collaboration and adaptation. The relational capabilities we have uncovered are the three main modes, namely performing collaborative processes, enabling matching functions and close partnerships and facilitating co-location and coworking.

\section{Conclusion}

This paper addressed the unfolding of digital transformation process in an industrial incumbent organization, seen as a process of adapting digital innovations around a platform-based digital infrastructure in partnership with an entrepreneurial firm. The collaboration between the entrepreneurial firm and the incumbent during the innovation cycles and platform development was extensive.

Our contribution to IS research is a better understanding of how complex and dynamic collaborative relationships emerge and evolve around digital platforms that are central to digital transformations. The findings and contributions are generalizable to other capital-intensive industries and B2B platformization. The limitation of the study is that we conducted a retrospective case study rather than followed the digital transformation and platformization as an ethnographic study. A more detailed account of the different relations between the industrial firm and the strategic partner is a topic for future research. Future studies should uncover the practices involved in the digital transformation and the collaborative change efforts between industrial firms and their strategic partners. 


\section{References}

[1] L. Kappelman, V. Johnson, R. Torres, C. Maurer, and E. McLean, "A study of information systems issues, practices, and leadership in Europe," European Journal of Information Systems, vol. 28, no. 1, pp. 26-42, 2019/01/02 2019, doi: 10.1080/0960085X.2018.1497929.

[2] S. Chanias, M. D. Myers, and T. Hess, "Digital transformation strategy making in pre-digital organizations: The case of a financial services provider," The Journal of Strategic Information Systems, vol. 28, no. 1, pp. 17-33, 2019/03/01/ 2019, doi: https://doi.org/10.1016/j.jsis.2018.11.003.

[3] B. Hinings, T. Gegenhuber, and R. Greenwood, "Digital innovation and transformation: An institutional perspective," Information and Organization, vol. 28, no. 1, pp. 52-61, 2018/03/01/ 2018, doi: https://doi.org/10.1016/i.infoandorg.2018.02.004.

[4] L. Li, F. Su, W. Zhang, and J.-Y. Mao, "Digital transformation by SME entrepreneurs: A capability perspective," Information Systems Journal, vol. 28, no. 6, pp. 1129-1157, 2018, doi: 10.1111/isj.12153.

[5] G. Vial, "Understanding digital transformation: A review and a research agenda," The Journal of Strategic Information Systems, vol. 28, no. 2, pp. 118-144, 2019/06/01/ 2019, doi: https://doi.org/10.1016/j.jsis.2019.01.003.

[6] N. V. Venkatraman, The Digital Matrix: New Rules for Business Transformation through Technology. Vancouver, BC, Canada: LifeTree Media, 2017.

[7] O. Hanseth and C. Ciborra, Eds. Risk, complexity and ICT. Edward Elgar Publishing, 2007.

[8] R. L. Törmer and S. Henningsson, "From Drift to Central Guidance: A Path Constitution Perspective on the Platformization of an Information Infrastructure," in 25th European Conference on Information Systems, 2018.

[9] K. H. Rolland, L. Mathiassen, and A. Rai, "Managing Digital Platforms in User Organizations: The Interactions Between Digital Options and Digital Debt," Information Systems Research, vol. 29, no. 2, pp. 419-443, 2018, doi: 10.1287/isre.2018.0788.

[10] O. Hanseth and K. Lyytinen, "Design Theory for Dynamic Complexity in Information Infrastructures: The Case of Building Internet," Journal of Information Technology, vol. 25, no. 1, pp. 1-19, 2010, doi: 10.1057/jit.2009.19.

[11] S. L. Star and K. Ruhleder, "Steps Toward an Ecology of Infrastructure: Design and Access for Large Information
Spaces," Information Systems Research, vol. 7, no. 1, pp. 111-134, 1996, doi: 10.1287/isre.7.1.111.

[12] C. U. Ciborra, Ed. From Control to Drift. The Dynamics of Corporate Information Infrastructures. 2000.

[13] O. Henfridsson and B. Bygstad, "The Generative Mechanisms of Digital Infrastructure Evolution," MIS Quarterly, vol. 37, no. 3, pp. 907-931, 2013. [Online]. Available: www.jstor.org/stable/43826006.

[14] E. Monteiro and O. Hanseth, "Social Shaping of Information Infrastructure: On Being Specific about the Technology," in Information Technology and Changes in Organizational Work: Proceedings of the IFIP WG8.2 working conference on information technology and changes in organizational work, December 1995, W. J. Orlikowski, G. Walsham, M. R. Jones, and J. I. Degross Eds. Boston, MA: Springer US, 1996, pp. 325-343.

[15] P. Constantinides, O. Henfridsson, and G. G. Parker, "Introduction-Platforms and Infrastructures in the Digital Age," Information Systems Research, vol. 29, no. 2, pp. 381-400, 2018, doi: 10.1287/isre.2018.0794.

[16] R. W. Gregory, H.-T. Wagner, S. Tumbas, and K. Drechsler, "At the Crossroads between Digital Innovation and Digital Transformation," in International Conference on Information Systems (ICIS), Munich, Germany, 2019.

[17] B. Bygstad and O. Hanseth, "Transforming digital infrastructures through platformization," in ECIS2018, 2018: AIS

[18] J. Wareham, P. B. Fox, and J. L. C. Giner, "Technology Ecosystem Governance," Organization Science, vol. 25, no. 4, pp. 1195-1215, 2014, doi: $10.1287 /$ orsc. 2014.0895

[19] R. W. Gregory, E. Kaganer, O. Henfridsson, and T. J. Ruch, "IT Consumerization and the Transformation of IT Governance," MIS Quarterly, vol. 42, no. 4, pp. 1225-1253, 2018, doi: 10.25300/MISQ/2018/13703.

[20] A. Benlian, W. J. Kettinger, A. Sunyaev, and T. J. Winkler, "Special Section: The Transformative Value of Cloud Computing: A Decoupling, Platformization, and Recombination Theoretical Framework," Journal of Management Information Systems, vol. 35, no. 3, pp. 719739, 2018/07/03 2018, doi: $10.1080 / 07421222.2018 .1481634$

[21] R. L. Törmer and S. Henningsson, "Platformization and Internationalization in the LEGO Group," in 53rd Hawaii International Conference on System Sciences, 2020

[22] D. Tilson, K. Lyytinen, and C. Sørensen, "Research Commentary-Digital Infrastructures: The Missing IS 
Research Agenda," Information Systems Research, vol. 21, no. 4, pp. 748-759, 2010, doi: 10.1287/isre.1100.0318.

[23] A. Tiwana, Platform Ecosystems: Aligning Architecture, Governance, and Strategy. San Francisco: Morgan Kaufmann, 2013.

[24] A. Ghazawneh and O. Henfridsson, "Balancing platform control and external contribution in third-party development: the boundary resources model," Information Systems Journal, vol. 23, no. 2, pp. 173-192, 2013, doi: 10.1111/j.1365-2575.2012.00406.x.

[25] B. Eaton, S. Elaluf-Calderwood, C. Sorensen, and Y. Yoo, "Distributed Tuning of Boundary Resources: The Case of Apple's iOS Service System," MIS Quarterly, vol. 39, no. 1, pp. 217-243, 2015.

[26] M. Aanestad, P. Vassilakopoulou, and E. Øvrelid, "Collaborative Innovation in Healthcare: Boundary Resources for Peripheral Actors," in ICIS 2019, 2019.

[27] Y. S. Lincoln and E. G. Guba, Naturalistic inquiry. Beverly Hills, CA: Sage, 1985.

[28] M. Alvesson and D. Kärreman, "Constructing mystery: Empirical matters in theory development," Academy of Management Review, vol. 32, no. 4, pp. 12651281, 2007. [Online]. Available: http://search.ebscohost.com/login.aspx?direct=true $\& \mathrm{db}=\mathrm{bth}$ $\underline{\mathrm{AN}}=26586822 \&$ site $=$ bsi-live .

[29] M. H. Agar, The Professional Stranger. An informal Introduction to Ethnography, Second ed. San Diego: Academic Press, 1996.

[30] S. Nambisan, K. Lyytinen, A. Majchrzak, and M. Song, "Digital Innovation Management: Reinventing Innovation Management Research in a Digital World," MIS Quarterly, vol. 41, no. 1, 2017, doi: 10.25300/MISQ/2017/41:1.03.

[31] S. Nambisan and M. Sawhney, "Orchestration processes in network-centric innovation : Evidence from the field," Academy of Management Perspectives, vol. 25, no. 3, pp. 40-57, 2011, doi: https://doi.org/10.5465/AMP.2011.63886529.

[32] M. Kohtamäki, V. Parida, P. Oghazi, H. Gebauer, and T. Baines, "Digital servitization business models in ecosystems: A theory of the firm," Journal of Business Research, vol. 104, pp. 380-392, 2019/11/01/ 2019, doi: https://doi.org/10.1016/j.jbusres.2019.06.027.

[33] M. Paiola and H. Gebauer, "Internet of things technologies, digital servitization and business model innovation in BtoB manufacturing firms," Industrial Marketing Management, 2020/03/21/ 2020, doi: https://doi.org/10.1016/j.indmarman.2020.03.009.
[34] M. Hasselblatt, T. Huikkola, M. Kohtamäki, and D. Nickell, "Modeling manufacturer's capabilities for the Internet of Things," Journal of Business \& Industrial Marketing, vol. 33, no. 6, pp. 822-836, 2018, doi: doi:10.1108/JBIM-11-2015-0225.

[35] S. Nambisan, D. Siegel, and M. Kenney, "On open innovation, platforms, and entrepreneurship," Strategic Entrepreneurship Journal, vol. 12, no. 3, pp. 354-368, 2018, doi: 10.1002/sej.1300. 